\title{
Herbivore dung deposit counts around drinking troughs in the Kruger National Park
}

\author{
I. Thrash, G.K. ThERON and J. DU P. BOTHMA
}

Thrash. I.. G.K. Theron and J. du P. Bothma. 1993. Herbivore dung deposit counts around drinking troughs in the Kruger National Park. Koedoe 36(1): 87-93. Pretoria. ISSN 0075-6458.

The density of deposits of dung of indigenous large herbivores was measured in transects starting at drinking troughs in the Kruger National Park. The aim was to test whether a relationship exists between intensity of (large indigenous) herbivore use and distance from drinking troughs. There was a significant positive relationship between intensity of herbivore use and distance from the troughs. The variance was too high, however, to detect relationships at individual transects or to warrant further modelling of the relationship. It was concluded that there was indeed a slight concentration of large herbivore rangeland use around the troughs.

Key words: dung deposits, drinking troughs, Kruger National Park, watering points, windmills. dung. habitat use.

I. Thrash. G.K. Theron and J. du P. Bothma. Centre for Wildlife Research, University of Pretoria, Pretoria. 0002, Republic of South Africa.

\section{Introduction}

During the course of their daily activities, including foraging, resting, defending territories, migrating, and drinking, herbivores spend different amounts of time in different parts of their range. Herbivore use intensity of rangeland is an index of the biomass of animals per unit time spent in a designated area. The impact of large herbivores on the vegetation and soil of an area is expected to be proportional to the herbivore use intensity. It is thus a useful parameter with which to interpret vegetation patterns. As many large herbivores in the Kruger National Park drink once every one to two days (Young 1970) permanent watering points are expected to become foci of high levels of herbivore use in the dry season, when temporary watering points dry up. Significant relationships with distance from water have been shown for the herbaceous vegetation community composition, basal cover and herbaceous forage and fuel production potential in the Kruger National Park (Thrash et al. 1993, unpublished). The cause of these relationships was postu- lated to be a decreasing gradient in rangeland use by herbivores, away from watering points. A relationship between herbivore use intensity and distance from water has not previously been shown, however.

Herbivore use intensity is difficult to measure directly and indices are usually used. Mass of dung is the most commonly used of the indices although density of dung deposits can also be used. According to Neff (1968) these are acceptable indices of the time spent by large herbivores in an area. Dung mass and dung deposit density have the advantage over other indices in that the mean herbivore use intensity over a period of several months is obtained.

The objective of the study was to test whether a relationship exists between herbivore use intensity and distance from drinking troughs.

For the purposes of this paper all primarily herbivorous large mammals (Eltringham 1979) that occur in the Kruger National Park are large herbivores. The orders Hyracoidea, 


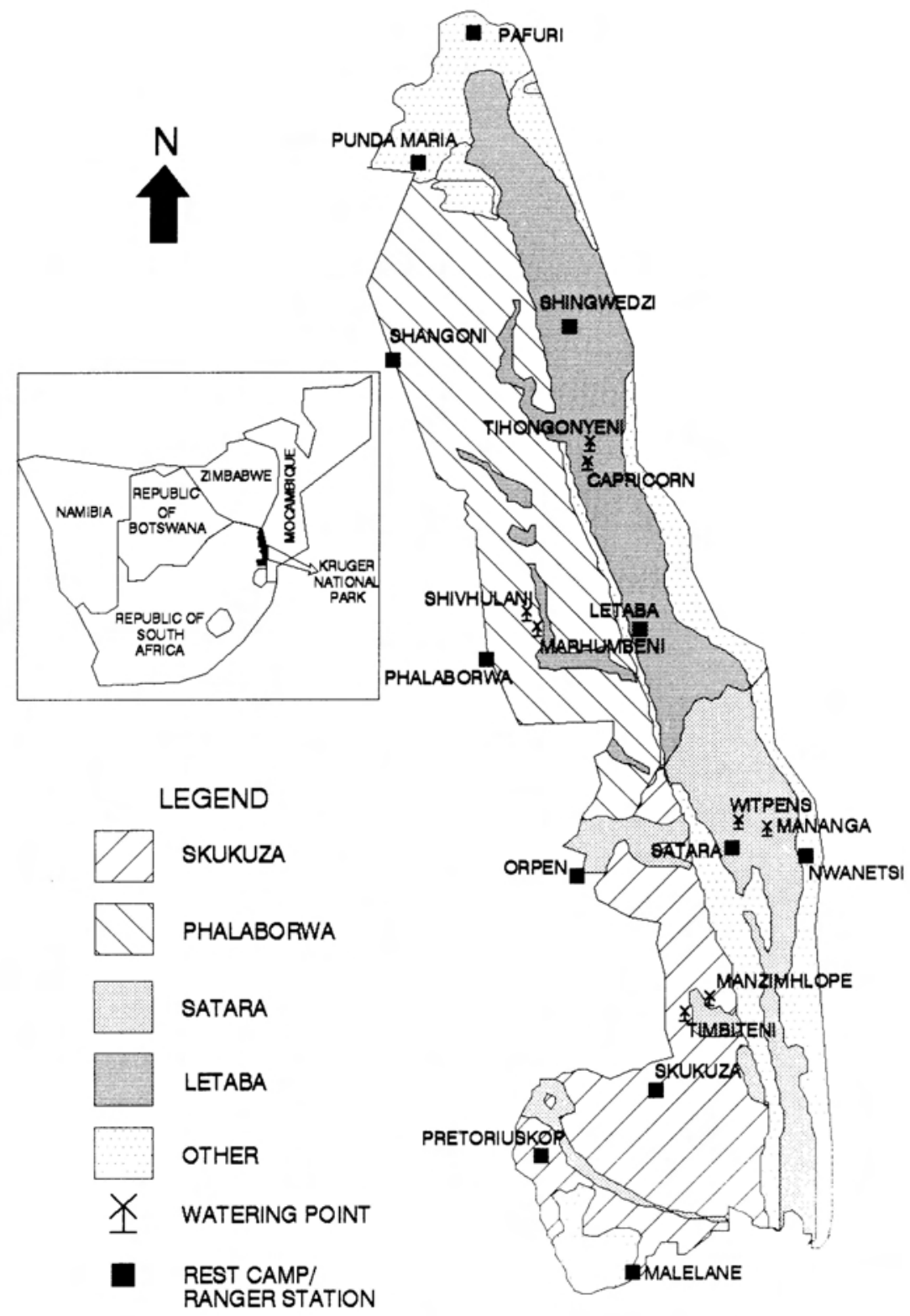

Fig. 1. The Kruger National Park, Republic of South Africa, including the four main land systems (after Venter 1990) and the eight artificial watering points surveyed in this study (1989). 
Proboscidea, Perissodactyla and Artiodactyla are included.

\section{Study area}

The Kruger National Park has been classified into 11 land systems by Venter (1990). The four largest, the Skukuza (Timbiteni \& Manzimhlope watering points), Satara (Mananga \& Witpens watering points), Letaba (Tihongonyeni \& Capricorn watering points) and Phalaborwa (Marhumbeni \& Shivhulani watering points) land systems, were sampled. The Skukuza land system has a relatively high mean annual rainfall $(550 \mathrm{~mm})$ and lies on granitoid rocks; the Satara land system also has a relatively high mean annual rainfall $(550 \mathrm{~mm})$, and lies on basaltic rocks; the Phalaborwa land system has a lower mean annual rainfall $(491 \mathrm{~mm})$ and lies on granitic rocks and the Letaba land system has an intermediate mean annual rainfall $(530 \mathrm{~mm})$ and lies on basaltic rocks.

\section{Methods}

Two artificial watering points were chosen in each of the four largest land systems of Venter (1990)(Fig. 1). The area around each watering point was classified by soil type according to the taxonomic soil classification system (Soil Classification Working Group 1991). A transect starting at the drinking trough and radiating away from it, keeping to the same soil type, was placed at each watering point.

Surveys were done in July 1989. Plots in the transects were set out in four parallel rows, $5 \mathrm{~m}$ apart, radiating from the watering points. Plots within rows were 10 $\mathrm{m}$ apart. The plots were circular with a $2 \mathrm{~m}$ radius. Dung deposits deteriorate rapidly in the wet season, lasting for as little as a week (Weir 1971). Little dung was therefore present at the beginning of the dry season and it was not judged necessary to clear all transects of old dung deposits at the beginning of the dry season.

All the dung deposits, of all large herbivore types, of which the centres fell within the plots were identified and recorded. Blue wildebeest (Connochaetes taurinus), buffalo (Syncerus caffer), Burchell's zebra (Equus burchelli), common duiker (Sylvicapra grimmia), elephant (Loxodonta africana), giraffe (Giraffa camelopardalis), impala (Aepyceros melampus), kudu (Tragelaphus strepsiceros), sable antelope (Hippotragus niger), steenbok (Raphicerus (ampestris), tsessebe (Damaliscus lunatus), waterbuck (Kobus ellipsiprymnus) and warthog (Phacochoerus aethiopicus) dung deposits were counted. Mean dung deposit densities were calculated by dividing the mean number of dung deposits in each set of four plots equidistant from the water by the area of the plots.

The relationship of the mean density of dung deposits of each large herbivore type with distance from water was tested at each watering point with regression analyses and a logarithmic transformation of distance from water.

A herbivore use intensity score for each distance from water increment was calculated by weighting the mean density of dung deposits in the four plots equidistant from the water for each herbivore species by the energy requirement (Meissner 1982) for that species.

A trial to determine the correlation between this herbivore use intensity score and the mass of herbivore dung was done at Manzimhlope. The $15 \mathrm{~m}$ wide transect beginning at the trough and radiating out from it was cleared of all dung deposits at the beginning of the dry season. The dung deposits that had accumulated in three months were counted. dried and massed. Correlation analysis was carried out on the total mass of dung and the herbivore use intensity score was calculated from the density of dung deposits of each herbivore type.

The herbivore use intensity scores were tested for a functional relationship with distance from water with multiple regression analysis, with dummy variables (Montgomery \& Peck 1982) coding for watering points and a logarithmic transformation of distance from water (Andrew \& Lange 1986). The null hypothesis that there was no functional relationship was rejected if $P \leq 0,05$.

\section{Results}

The mean dung deposit density was determined for the rangeland at 221 points along eight transects. There were significant logarithmic relationships between the density of dung deposits of a few large herbivore species and distance from water at some of the watering points (Table 1).

There was a high $(R=0,83)$ correlation between dung mass and herbivore use intensity score in the trial done at Manzimhlope, indicating that the two parameters give similar information on the herbivore use intensity and that only one need be measured.

The variance in the dung density data remained high, even after a herbivore use intensity score incorporating all herbivores, was plotted against distance from the troughs (Fig. 2). When tested individually, the only watering point at which there was a significant relationship between herbivore use in- 
Table 1

Mean dry season dung deposit densities (number per hectare) and herbivore use intensity scores along transects at eight watering points in the Kruger National Park in 1989. Only the herbivores of which dung was present in all transects are shown.

\begin{tabular}{|c|c|c|c|c|c|}
\hline \multirow{2}{*}{$\begin{array}{c}\text { Watering } \\
\text { point }\end{array}$} & \multicolumn{4}{|c|}{ Mean dung deposit density } & \multirow{2}{*}{$\begin{array}{l}\text { Herbivore use } \\
\text { intensity } \\
\text { score }\end{array}$} \\
\hline & Impala & Buffalo & BlueWildebeest & Zebra & \\
\hline Timbiteni & 1388 & $477^{*}$ & 465 & 248 & 1.85 \\
\hline Manzimhlope & 113 & 2109 & 13 & 60 & 3,67 \\
\hline Mananga & $92 *$ & 28 & 740 & 442 & 1.10 \\
\hline Witpens & 13 & 199 & 351 & $484^{*}$ & 1,10 \\
\hline Marhumbeni & $129^{*}$ & 1681 & 30 & 20 & 2,92 \\
\hline Shivhulani & $955^{*}$ & $565^{*}$ & 16 & 501 & $1,84^{*}$ \\
\hline Capricorn & 139 & 1094 & $169^{*}$ & 219 & 2,25 \\
\hline Tihongonyeni & 92 & 103 & 1210 & 402 & 1.85 \\
\hline
\end{tabular}

* Significant relationships at $(P \leq 0.05)$

tensity score and distance from water was Shivhulani $(P=0,0037)$.

A small, but significant $(P=0,0291)$, portion of the total variance in herbivore use intensity score was, however, explained by the negative effect of distance from water in the multiple regression analysis with dummy variables coding for watering points.

\section{Discussion}

Dung deposit counts have been successfully used for determining the use intensity of habitats in several studies (Neff 1968; Parris 1976; Wood 1988; Edge \& Marcum 1989; Welch 1990; Jachmann 1991). In others, however, they were found to be of limited value (Fuller 1991, 1992).

Dung deposit counts may not be suitable for detecting increased herbivore use intensity around watering points. Although Child et al. (1971) concluded that there were greater concentrations of animals near water in the Kalahari Gemsbok National Park, relationships between dung deposit density and distance from water were often not statistically significant. Weir (1971) found that the relationships between dung deposit density and distance from water were often positive in the first $1,5 \mathrm{~km}$ of a transect radiating out from a pan, becoming negative farther away.

Although a weak, but significant, negative relationship was detected in a combined data set from all watering points in our study, the data were too variable to be useful for modelling the herbivore use intensity around watering points or for testing for relationships at each watering point separately. If the use of rangeland by herbivores is to be satisfactorily modelled, then another index less biased by uncontrollable factors will have to be used. Lange (1969) measured track density using aerial photographs around watering points in Australia. Counts of herbivores from the air is another possibility (Western 1975).

Our results show that although watering points do have a slight effect, they are relatively unimportant in determining the distribution of large herbivore use intensity of rangeland in the dry season in the Kruger National Park. This contradicts a considerable amount of other direct and indirect evidence (Van der Schijff 1959; Young 1970; Smuts 1972; Joubert 1976; Venter 1990; Thrash et al. 1993, unpublished), however, and it is concluded that our results were biased. 

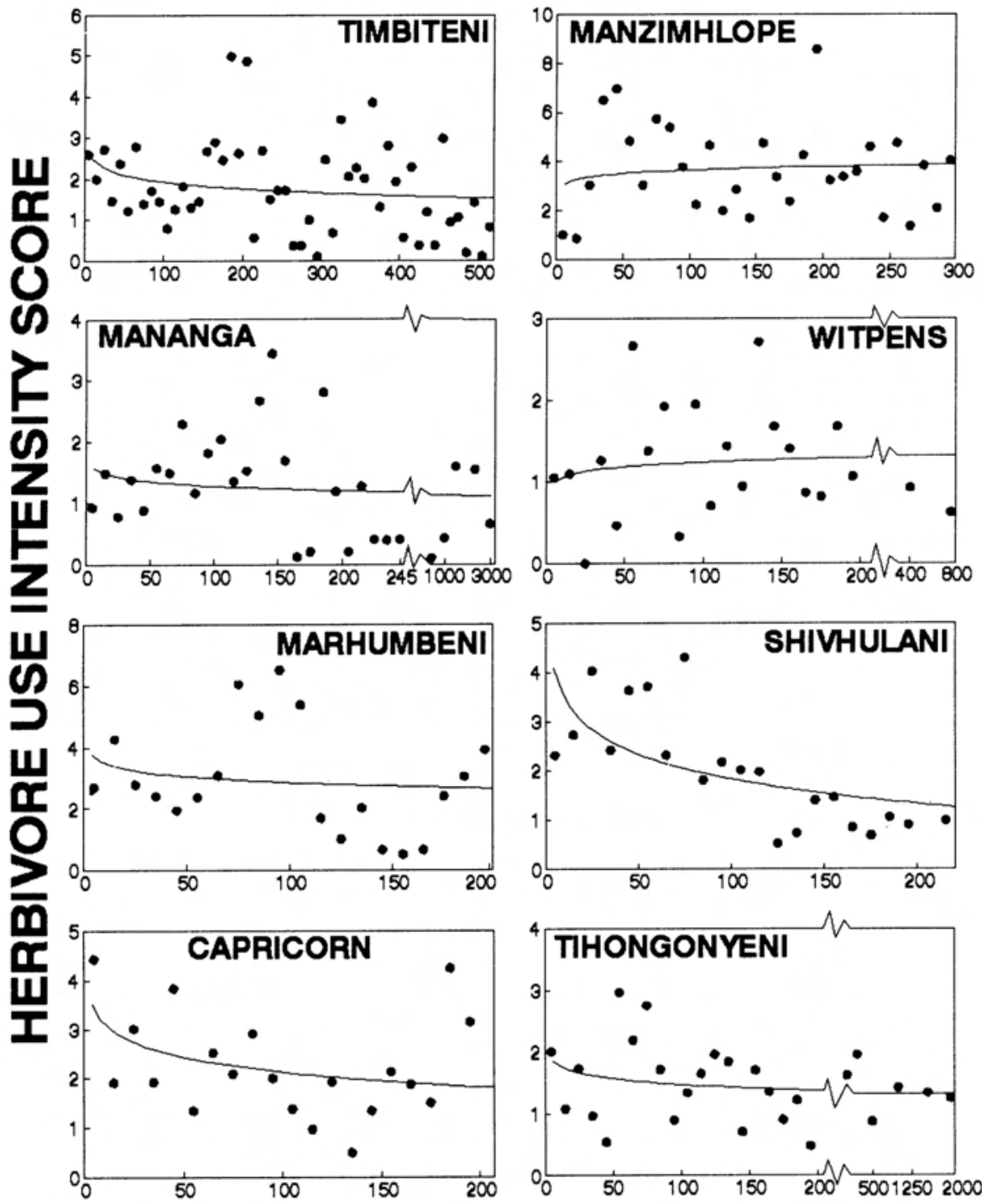

DISTANCE FROM WATER

Fig. 2. Herbivore use intensity score (density of dung deposits weighted by energy requirement) as a function of distance from water $(\mathrm{m})$ at eight artificial watering points in the Kruger National Park (1989). 
Using dung deposit density as an index of herbivore use intensily requires certain assumptions. These include those of constant rates of defecation and deterioration of deposits along the transects. It is unlikely that the defecation rates of herbivores will remain constant during the daily pattern of feeding at a distance from water, moving to water. drinking and moving away from water again. The length of time that a dung deposit remains recognisable is strongly correlated to the actions of insects, the degree of trampling and the amount of vegetation protecting the deposit (Neff 1968; Weir 1971). As positive relationships have been shown for herbaceous vegetation basal cover with distance from water in the Kruger National Park (Thrash etal. unpublished) and trampling and insect activity in Zimbabwe (Weir 1971) there is likely to be a negative relationship between distance from water and the rate of deterioration of dung deposits. Weir (1971) found that both trampling and increased termite activity were important masking factors of the accumulation of dung around watering points. A relationship, stronger than the results suggest, therefore, probably exists between herbivore use intensity and distance from water.

Mean herbivore use intensity was relatively high at Manzimhlope, Marhumbeni and Capricorn (Table 1). The impact of herbivores on the vegetation around these watering points, however, was generally less than at the other watering points (Thrash et al. 1993: unpublished). Manzimhlope. Marhumbeni and Capricorn also had high densities of buffalo dung deposits and it seems that buffalo dominated herbivore use intensity scores when present. This is probably because of this herbivore's habit of resting near water and defecating before leaving (Young 1970), its high energy requirement score (Meissner 1982) and its tendency to form large herds. As the mean defecation rates of a variety of large herbivores, for which this parameter is known. do not vary considerably (e.g. the mean defecation rate of domestic cattle falls within the range of that for deer)(Neff 1968) it is unlikely that this phenomenon is because of a high defecation rate, relative to the other large herbivore types. for buffalo.

\section{Conclusions}

There was a significant positive relationship between herbivore use intensity and distance from the troughs. The variance was too high, however, to detect relationships at individual transects or to warrant further modelling of the relationship. Dung deposit counts may not be suitable for detecting increased herbjvore use intensity around watering points. A relationship, stronger than the results suggest, therefore, probably exists between herbivore use intensity and distance from water.

\section{Acknowledgements}

We are indebted to the staft of the Kruger National Park for assistance and to the National Parks Board for permission to work in the study area. The National Parks Board and the Centre for Wildlife Research provided financial support.

\section{References}

ANDKEW, M.H. AND R.T. Lancis, 1986, Development of a new piosphere in arid chenopod shrubland grazed by sheep. 1. Changes to the soil surfice. Australian. Journal of Ecology 3+ 336-339.

Chun, G., R. PArris ind E.A.N. LE Riche. 1971. Use of mineralised water by Kalahari wildlife and its effects on habitats. East Afican Wildlife Joumal 9: $125-142$.

Edge. W.D. And C.L. Marcum, 1989. Determining elk distribution with pellel-group and telemetry techniques. The Jominal of Wildife Managentent 53: 621-624.

ELTRINGHAM, S.K. 1979. The ecology and conservanion of large Afritan mammals. London: The MacMillan Press Lid.

FulLER, T.K. 1991. Do pellet counts index whitelailed deer numbers and population changes? The Journal of Wildifo Manasemen 55: 393-396.

FuLL.FR. T.K, 1992. Do pellet counts index whitetailed deer numbers and population changes?: A reply. The Journal of Wildlife Management 56: 613 .

JACIMANv. H. 1991. Evaluation of four survey methods for estimating elk distribution relative to topographic and disturbance factors. African Journal of Ecology 29; 188-195.

JOABERT. S.C.J. 1976. The population ecology of the roan antelope. Hippotragus equinus equinus 
(Desmarest, 1804), in the Kruger National Park. D.Sc. thesis, University of Pretoria, Pretoria.

LANGE, R.T. 1969. The piosphere, sheep track and dung patterns. Journal of Rangeland Management 22: 396-400.

MeissnfR, H.H. 1982. Theory and application of a method to calculate forage intake of wild southern African ungulates for purposes of estimating carrying capacity. South African Journal of Wildlife Research 12:41-47.

Montgomery. D.C. And E.A. Peck. 1982. Introduction to linear regression analysis. New York: John Wiley.

NEFF, D.J. 1968. The pellet-group count technique for big game trend, census, and distribution: A review. The Journal of Wildlife Management 32: 597-614.

PARRIS, R. 1976. A study of the major components of the Kalahari pan ecosystem. M.Sc. thesis. University of Pretoria, Pretoria.

Smuts, G.L. 1972. Seasonal movements, migration and age determination of Burchell's zehra (Equus burchelli antiquorum, H. Smith. 1841) in the Kruger National Park. M.Sc. thesis, University of Pretoria, Pretoria.

Soil Classification Working Group. 1991. Soil classification: a taxonomic system for South Africa. Memoirs on the Agricultural Natural Resources of South Africa No. 15. Department of Agricultural Development, Pretoria.

Thrash, I., G.K. Theron and J. du P. Bothma. 1993. (in press). Impact of water provision on herba- ceous plant community composition in Kruger National Park. Journal of the Grassland Society of southern Africa $10(2)$.

VAN DER SCHIJFF, H.P. 1959. Weidingsmoontlikhede en weidingsprobleme in die Nasionale Krugerwiltuin. Koedoe 2: 96-127.

Venter. F.J. 1990. A classification of land for management planning in the Kruger National Park. Ph.D. thesis. University of South Africa. Pretoria.

WEIR, J.S. 1971. The effect of creating additional water supplies in a Central African National Park. Pp. 367-385. In: Duffey, E. ANd Watt, A.S. (eds.). The scientific management of animal and plant communities for conservation. Oxford: Blackwell Scientific Publications.

Welch, D., B.W. Staines, D.C. Catt and D. Scott. 1990. Habitat usage by red (Cerrus elaphus) and roe (Capreolus capreolus) deer in a Scottish Sitka spruce population. Journal of Zoology 221: 453 476.

Western, D. 1975. Water availability and its influence on the structure and dynamics of a savannah large mammal community. East African Wildlife Journal. 13: 265-286.

WoOD, D.H. 1988. Estimating rabbit density by counting dung pellets. Australian Wildlife Research 15: 665-671.

Young, E. 1970. Water as 'n faktor in die ekologie ran wild in die Nasionale Krugerwiltuin. D.Sc. (Wildlife Management) thesis, University of Pretoria, Pretoria. 